\title{
Alcohol screening instruments in elderly male: a population-based survey in metropolitan São Paulo, Brazil
}

\section{Instrumentos de detecção do uso de álcool em homens idosos: um estudo populacional na região metropolitana de São Paulo, Brasil}

\author{
Janaina Barbosa de Oliveira, ${ }^{1}$ Jair Lício Ferreira Santos, ${ }^{2}$ Florence Kerr-Corrêa, ${ }^{3}$ Maria Odete Simão, ${ }^{3}$ Maria \\ Cristina Pereira Lima ${ }^{3}$ \\ ${ }^{1}$ Programa de Pós-Graduação em Saúde Mental, Universidade de São Paulo (USP), Ribeirão Preto, SP, Brazil \\ 2 Departament of Social Medicine, Universidade de São Paulo (USP), Ribeirão Preto, SP, Brazil \\ ${ }^{3}$ Departamento de Neurology, Psycology and Psychiatry, Universidade Estadual Paulista (UNESP), Botucatu, SP, Brazil
}

\begin{abstract}
Objective: This study compares the efficacy of the AUDIT (gold standard) with the more easily and quickly applied instruments CAGE, TWEAK, and T-ACE for men aged $\geq 60$ using data from a representative stratified sample of the general population of metropolitan São Paulo. Method: The GENACIS questionnaire was administered to a total sample of 2,083 people aged over 18 , with a response rate of $74.5 \%$. The elderly male sample consisted of 169 men. Sensitivity, specificity, positive and negative predictive values, area under the receiver operating characteristic curve, and confidence intervals were calculated for each instrument $(95 \% \mathrm{CI})$. Results: Respondents were predominantly married (81.7\%), had up to 11 years of education (61.3\%) and a monthly per capita income of up to 300 US dollars. Current abstinence rate was high $(61.6 \%)$ and $38 \%$ reported being former drinkers. There were no statistically significant differences among the instruments tested; however, the TWEAK had a higher area under the receiver operating characteristic curve (95\% CI; 0.90-0.99). Conclusion: Research in the general population with screening instruments is scarce, especially among the elderly. However, it can provide specific information concerning this age group and be useful in the formulation of policies and prevention strategies.
\end{abstract}

Descriptors: Psychometrics, Alcoholism; Men; Epidemiology; Geriatric psychiatry

\section{Resumo}

Objetivo: Este estudo compara a eficácia do AUDIT (padrão-ouro) com o CAGE, TWEAK, e T-ACE, instrumentos mais fáceis e rápidos de aplicar, entre homens com $\geq 60$ anos de idade, utilizando dados de uma amostra representativa estratificada da população da regiāo metropolitana de São Paulo. Método: Foi utilizado o questionário GENACIS em uma amostra total de 2.083 entrevistados de 18 anos ou mais de idade. A taxa de resposta foi de $74,5 \%$. A amostra de homens idosos ( $\geq 60$ anos) foi constituida por 169 homens. Foram calculados para cada instrumento a sensibilidade, especificidade, valor preditivo positivo e negativo, área sob a curva ROC (receiver-operating characteristic) e intervalos de confiança (IC 95\%). Resultados: Houve predominância de homens casados (81,7\%), com até 11 anos de estudo (61,3\%) e com renda per capita de até 300 dólares. $A$ taxa de abstinência atual foi alta (61,6\%), dos quais $38 \%$ relataram ter sido ex-bebedores. Não foram encontradas diferenças estatisticamente significativas entre os instrumentos testados. No entanto, o TWEAK apresentou maior área sob a curva ROC (0,95; IC 95\% 0,90-0,99). Conclusão: As pesquisas em população geral com instrumentos de rastreamento são escassas, principalmente entre idosos. No entanto, podem fornecer informaçôes específicas para essa faixa etária e são úteis para a formulação de políticas e estratégias de prevenção.

Descritores: Psicometria; Alcoolismo; Homens; Epidemiologia; Psiquiatria geriátrica

\section{Introduction}

Because the proportion of older people in the population is increasing, the total number of elderly with alcoholrelated problems is also expected to increase. Heavy alcohol use substantially contributes to morbidity, mortality, and hospitalizations in elderly people.
Although alcohol consumption is usually lower in the elderly than among younger individuals, its negative consequences can be greater due to aging-related physiological changes. The elderly have increased body fat and reduced non-fat mass and water, as well as decreased hepatic metabolism. ${ }^{1}$ Consequently, alcohol
Submitted: August 6, 2010

Accepted: November 11, 2010

\section{Correspondence}

Janaina Barbosa de Oliveira

Department of Neurology, Psychology and Psychiatry Botucatu Medical School, Universidade Estadual Paulista (UNESP) Botucatu, SP, Brazil

Phone: (+55 14) 3811-6260 Fax: (+55 14) 3815-6259

Email: janaina.btu@gmail.com 
blood levels tend to be higher in drinking elderly, who start to experience the adverse consequences of drinking even without increasing consumption. ${ }^{1}$ Despite the higher risk, it is estimated that $9 \%$ of the elderly have unhealthy drinking habits in the USA. ${ }^{2}$

Due to differences between young adults and the elderly, it has been suggested that those over 65 years of age should drink no more than one drink per day on average or two drinks in any single drinking session, if there are no contraindications due to diseases or medication use. ${ }^{3}$

In a Brazilian study, drinking five or more drinks per day was associated with falls, an important concern in elderly people. ${ }^{4}$ Men aged $\geq 65$ with a history of five years or more of heavy drinking at some time in their lives had an almost six-fold higher risk of suffering from psychiatric disorders. ${ }^{5}$ The risk of depression was almost four times as high and that of dementia was almost five times as high as that of individuals with no such history. ${ }^{6}$

Although alcohol-related problems are quite frequent in Brazil, their magnitude in the elderly remains unknown. General population surveys in Brazil have targeted younger age groups; therefore, the small number of older people in the samples reduces the statistical power of analyses related to them. Authors using regional samples in Brazil have estimated the prevalence of harmful drinking in the elderly as between $4.3 \%$ for both genders ${ }^{7}$ and $27 \%$ for men alone. ${ }^{8}$ Cross-sectional analyses of nationally representative data showed that, in those over 60 years of age, $10.4 \%$ reported drinking three or more drinks per occasion and $2.9 \%$ were alcohol dependents. ${ }^{9}$ Harmful alcohol use and dependence in older people are often not detected in the medical practice. The detection of alcohol-related problems in older patients has led researchers to develop and standardize screening instruments to be used specifically with the elderly. ${ }^{10}$ Most existing screening instruments were developed for young and middle-aged adults, where items often refer to alcohol problems among young men and cut-off points are defined for this age group.

Alcohol screening in older adults is likely to provide benefits at the individual level by helping patients and doctors take informed decisions. Benefits are also likely to appear at the populational level, with the findings of screening programs being used to guide public health initiatives. ${ }^{11}$

A systematic literature review showed that the CAGE was the most widely studied screening instrument, followed by the MAST or its variations and the AUDIT and its variations. ${ }^{11}$

The CAGE does seem suitable for the screening of alcoholrelated problems in older people. In some studies, when a score of two is used, sensitivity varies between $48 \%$ and $82 \%$ in hospital and nursing home patients, and specificity ranges between $82 \%$ and $99 \% \cdot{ }^{12-15}$ Luttrell et al. found that the CAGE had a low sensitivity (13\%) with a cut-off score of two, although displaying a high specificity (98\%). ${ }^{16} \mathrm{~A}$ Brazilian study with a sample of people aged $\geq 60$ found a positive predictive value of the CAGE (30.8\%), a sensitivity of $75 \%$, and a specificity of $74.3 \% .^{17}$

This study was conceived due to the lack of information regarding the screening of alcohol-related problems in Brazilian elderly. The aim was to compare the efficacy of the AUDIT (gold standard) with the more easily and quickly applied instruments CAGE, TWEAK, and T-ACE to identify alcohol use disorders in males aged $\geq 60$ years.

\section{Method}

This study is part of the international GENACIS project (Gender, Alcohol, and Culture: an International Study), a collaborative study supported by the Pan American Health Organization (PAHO) and conducted in different countries, including Brazil. ${ }^{18}$

This study is based on a cross-sectional survey in the general population of metropolitan São Paulo. According to data from the 2005 census of the Brazilian Institute of Geography and Statistics (IBGE), the metropolitan area of the city of São Paulo had a population of $19,130,455$, of which about $8 \%$ were men aged $\geq 60$ years. ${ }^{19}$ The area covers the capital of the state of São Paulo and another 38 counties, with a population of about two thirds of the entire state.

\section{Participants}

The sample was obtained through a two-stage randomization procedure: initially, census sectors were randomly selected, and then households. In this way, the sampling unit was the household, in which all persons aged 18 and above were eligible to be interviewed. The sample size was increased to allow for a $20 \%$ non-response rate, with an over-representation of those aged $\geq 60$ years, in accordance with the objectives of the study.

Table 1 - Socio-demographic characteristics of male subjects aged 60 or above in the metropolitan region of São Paulo, Brazil $(n=169)$

\begin{tabular}{lcc}
\hline $\begin{array}{l}\text { Men } \geq 60 \text { years old } \\
(\mathrm{n}=169 / 11.1 \%)\end{array}$ & $\mathbf{n}$ & $\%$ \\
\hline Marital status & 138 & 81.7 \\
Married & 16 & 9.5 \\
Widowed & 9 & 5.3 \\
Divorced & 6 & 3.5 \\
Never married & & \\
Education (years) & 28 & 16.7 \\
No schooling & 103 & 61.3 \\
Up to 11 & 37 & 22.0 \\
12 or more & & \\
Per capita income (dollars) & 55 & 33.7 \\
0 to 300 & 29 & 17.3 \\
301 to 600 & 36 & 21.4 \\
601 to 1200 & 49 & 27.6 \\
1201 or more & & \\
Pattern of alcohol use & 40 & 23.6 \\
Lifetime abstainer & 64 & 38.0 \\
Former drinker & 40 & 23.6 \\
1-2 drinks & 11 & 6.5 \\
3-4 drinks & 14 & 8.3 \\
5 or more drinks & & \\
\hline
\end{tabular}




\section{Assessment instruments}

The GENACIS questionnaire (available upon request) was used in the study. This questionnaire was developed by a group of researchers from several countries interested in comparing alcohol consumption patterns across genders in different contexts and cultures. It has already been described and used in Brazil ${ }^{20}$ and consists of 15 sections covering a number of variables such as socio-demographic characteristics, job experience, social networking, general health and life style, family history of alcohol consumption, mental health, smoking, and alcohol use (quantity, frequency, family context, and consequences).

Alcohol consumption variables: The grams of ethanol consumed per day were estimated from the self-reported drinking frequency, beverage type, and amount consumed based on the ethanol contents of standard drinks. Questions about alcohol consumption (beer, wine, liquor, etc.) were standardized to one drink unit of $13 \mathrm{~g}$ of ethanol, according to the average drink size in Brazil. Abstainers were defined as those who did not drink at all during the previous year. Light consumption was defined as 1-2 drinks per day on average; moderate consumption, as 3-4 drinks per day; and heavy consumption was defined as 5 or more drinks per day. All of the above categories were treated as mutually exclusive.

The GENACIS questionnaire provides enough information regarding the quantity and frequency of alcohol intake as well as information about the consequences of intake. The data collected with the questionnaire were used to establish the scores for each of the instruments below:

AUDIT (Alcohol Use Disorders Identification Test): the test contains 10 questions concerning the quantity and frequency of drinking, alcohol dependence, and related problems. With a score of eight or more, harmful alcohol use or dependence is suspected. The AUDIT has been developed for the World Health Organization to detect current problem drinking in young adults in primary care. ${ }^{21}$ The test's reliability and validity for older patients have not been assessed.

$C A G E$ : the name of this test is an acronym formed by the first letters of 'Cut-down', 'Annoyed', 'Guilty' and 'Eye-opener'. A score of two or more in the yes/no questions indicates harmful alcohol use or dependence. The CAGE was developed in 1970 by Ewing for young and middle-aged adults in hospital settings ${ }^{22}$ and was validated in 1974 by Mayfield. ${ }^{23}$ These authors did not report the reliability and validity of the CAGE for older hospital patients.

TWEAK: this test was developed as an alternative form of the MAST (Michigan Alcohol Screening Test) for women, eliminating questions more typically related to male behavior. ${ }^{24}$ It has five items and the name is an acronym formed by the first letters of the words 'Tolerance', 'Worried', 'Eye-opener', Amnesia', and 'K/Cut-down'. A cut-off point of two or more is considered as indicative of potential risky alcohol consumption..$^{25}$

T-ACE: some authors proposed a modification of the CAGE to be used with pregnant women, ${ }^{26}$ named T-ACE. The test has only four questions, with a cut-off point of two or more positive responses. The name is an acronym formed by the first letters of the words 'Tolerance', 'Annoyance', 'Cut-down', and 'Eye-opener'. It was validated in Brazil in 2002. ${ }^{27}$

\section{Procedures}

All interviewers had previous experience in household surveys and were specifically trained and supervised on a monthly basis during the period of the study. Ten percent of the interviews were double-checked by supervisors for quality control. In an attempt to overcome refusals to participate, letters with information on the objectives, importance, and expected impact of the study, along with the credentials and contact details of the main investigators, were sent to those who had refused to participate in a first approach. The project's website address (www.viverbem. fmb.unesp.br/projeto_genacis.asp) was also included in the letter so that study subjects could obtain detailed information.

\section{Data analysis}

A test of association which accounts for the sample design (RaoScott) was used for the univariate analysis ( $p<0.05$; confidence interval of $95 \%$ ). The following parameters were evaluated for each instrument and respective intervals of confidence: sensitivity $(S)$, specificity (E), positive and negative predictive values (PPV and NPV), and area under the receiver operating characteristic (ROC) curve.

The project was approved by the Research Ethics Committee of Botucatu Medical School (UNESP), on September 13, 2004 (OF 457/2004).

\section{Results}

The interviews were conducted between October 2005 and March 2007. The final sample included 2,083 people, with a response rate of $74.5 \%$, including 169 men aged $\geq 60(11.1 \%)$.

Most of the male sample aged $\geq 60$ years were married $(81.7 \%)$, had up to 11 years of education $(61.3 \%)$, and had a monthly income of up to 300 dollars per capita. The majority were former drinkers (38\%) - see Table 1.

The CAGE had a low sensitivity (25.0) and a high specificity (100.0) for this sample, while the TWEAK and the T-ACE had a sensitivity level of 0.75 , with the T-ACE having the higher specificity of the two. The positive predictive value for the standard cut-off point $(\geq 2)$ was much higher in the TWEAK (75.0), while the negative predictive values were similar in all three instruments. The correct classification rate was also higher in the TWEAK (96.4) - see Table 2.

No statistically significant differences were identified between the three instruments $(\mathrm{p}=0.14)$. However, although no instrument proved superior to the others, the TWEAK had the highest area under the ROC curve, of 0.95 (95\% CI; 0.90-0.99). The CAGE had the worst performance of the three tests, with an area under the ROC curve of 0.85 (95\% CI; 0.72-0.98).

\section{Discussion}

The main findings of this show that there were no statistically significant differences among the three instruments; however, the TWEAK presented the highest area under the ROC curve to 
Table 2 - Psychometric properties of the CAGE, TWEAK, and T-ACE using the instruments' standard cutoff points ( $\geq 2)$ compared with the AUDIT $(\geq 8)$ for male subjects aged 60 or above in the metropolitan region of São Paulo, Brazil $(n=169)$

\begin{tabular}{lccc}
\hline Men $\geq \mathbf{6 0}$ years old $(\mathrm{n}=169)$ & CAGE $(\%)$ & TWEAK (\%) & T-ACE (\%) \\
\hline Sensitivity & 25.0 & 75.0 & 75.0 \\
Specificity & 100.0 & 98.1 & 95.5 \\
Positive predictive value & - & 75.0 & 56.2 \\
Negative predictive value & 94.6 & 98.1 & 98.0 \\
Correct classification rate & 94.7 & 96.4 & 94.1 \\
Area under the ROC curve & 0.85 & 0.95 & 0.94 \\
$(95 \% \mathrm{Cl})$ & $(0.72-0.98)$ & $(0.90-0.99)$ & $(0.89-0.98)$ \\
\hline
\end{tabular}

$p=0.1432$ chi square with Bonferroni correction.

detect hazardous alcohol use in male subjects aged $\geq 60$, whereas the CAGE had the worst performance among the instruments assessed. This result may be due to the small sample of drinkers in the age of 60 and above, which is a characteristic of the Brazilian population, where about $40 \%$ of men are non-drinkers. ${ }^{28}$

The majority of studies involving the elderly did not investigate the efficacy of the TWEAK and the T-ACE. The most commonly evaluated instruments were the CAGE, ${ }^{10,16,29-31}$ the AUDIT, ${ }^{32,33}$ and the MAST-G (Michigan Alcohol Screening Test - Geriatric Version). ${ }^{16}$

A review on instruments for detecting alcohol abuse and dependence in the elderly reported that the MAST-G and particularly the CAGE seem appropriate, while the AUDIT and the MAST do not seem adequate for screening the elderly in clinical settings. ${ }^{5}$ Another study reported that the CAGE and the MAST-G are unsuited to identify early stage (hazardous or harmful) alcohol use among the elderly, and that the AUDIT may prove more useful in identifying early stage problem drinking, although the MAST-G and the CAGE have been shown to outperform the AUDIT in detecting alcohol abuse and dependence in elderly males. ${ }^{1}$

Rigler showed that several brief screening tools for alcoholism do not distinguish recent from past drinking behavior, and in patients aged 60 and above, the CAGE is not sensitive, usually detecting only binge drinking. ${ }^{34}$ The CAGE questionnaire is not suitable for detecting daily alcohol intake below $80 \mathrm{~g}$, and is thus considered a valid screening instrument for dependent drinkers only. ${ }^{35}$

In our study, the majority of males aged $\geq 60$ were former drinkers, lifetime abstainers, or light drinkers. Our results corroborate those of Naik et al. ${ }^{36}$ and Mangion et al., ${ }^{37}$ which reported that the CAGE is not an effective screening instrument for older UK inpatients, but constrast with findings in the USA by Buchsbaum et al. ${ }^{12}$ and Joseph et al., ${ }^{14}$ who found the CAGE to have satisfactory sensitivity levels of 0.70 and 0.82 , respectively. Overall, the efficacy of the CAGE has been examined in many studies involving a total of over 6,000 individuals and yielding a median sensitivity of $66.5 \%$ and median specificity of $89 \%{ }^{11}$

Moore et al. suggested that a combination of screening measures might be able to identify a higher number of elderly men with possible alcohol use disorders than any isolated measure. ${ }^{38}$

Inconsistent findings across studies may reflect methodological divergences. In studies comparing multiple screening questionnaires or using interview criterion standards for both alcohol consumption and related problems, the order of screening questions and interview components may affect responses. ${ }^{39}$

Several factors contribute to the decline in alcohol consumption in the elderly; these include increased vulnerability to organic harm, comorbid conditions, and polypharmacy. However, other factors may emerge that could lead to new cases of alcoholism in later life; for instance, stressors such as retirement and bereavement. ${ }^{33}$

The presentation of elderly people with alcohol use disorders may be untypical (e.g. falls, confusion, depression) or 'masked' by comorbid physical or psychiatric illnesses. ${ }^{11}$ Factors which affect the performance of alcohol screening instruments include culture, clinical setting, patient characteristics, and the prevalence of alcohol use disorders in the study population. ${ }^{11}$ Consideration should be given to cognitive disorders, an important part of geriatric-specific morbidity, which could lead to a misunderstanding of any test item, thereby increasing the recall bias.

Furthermore, stigma on alcohol use could increase underreporting, yielding a much lower sensitivity.

Screening instruments are an important tool in detecting alcohol use disorders. Although the TWEAK performed better in our study, this difference was not statistically significant. More studies with larger samples are needed to identify the most efficient instruments to detect alcohol-related problems in the elderly. The frequent health problems found in later life and the increasing elderly population make the problem of alcohol use a relevant question in public health.

The small number of subjects positively identified with the instruments assessed constitutes a limitation of this study in that it reduces the statistical power of the analyses. Another fundamental question is the reliability of subjective reports. Despite the fact that some authors reported high denial rates in dependents of alcohol or other drugs, the literature has demonstrated that, under adequate conditions, information collected tends to be accurate, with a high level of agreement between self-reported data from problem drinkers and other sources of information, such as family members and spouses. ${ }^{40}$

The study was conducted over one year, stratified by districts, and the total sample is representative of the socioeconomic and educational levels of around 3.5 million people. Thus, the 
results can be generalized to other large urban centers, but do not necessarily reflect the patterns of Brazilian rural areas.

\section{Acknowledgements}

This study was funded by São Paulo State Research Support Foundation (FAPESP - grant 04/11729-2 and 07/56124-9 doctoral scholarship to JBO). The PAHO coordinated the survey in different countries and supported part of the training in Brazil.

\section{Disclosures}

\begin{tabular}{|c|c|c|c|c|c|c|c|}
\hline $\begin{array}{c}\text { Writing group } \\
\text { member }\end{array}$ & Employment & $\begin{array}{l}\text { Research } \\
\text { grant }^{1}\end{array}$ & $\begin{array}{l}\text { Other research } \\
\text { grant or medical } \\
\text { continuous } \\
\text { education }^{2}\end{array}$ & Speaker's honoraria & $\begin{array}{l}\text { Ownership } \\
\text { interest }\end{array}$ & $\begin{array}{l}\text { Consultant/ } \\
\text { Advisory } \\
\text { board }\end{array}$ & Other $^{3}$ \\
\hline $\begin{array}{l}\text { Janaina } \\
\text { Barbosa de } \\
\text { Oliveira }\end{array}$ & USP & $\begin{array}{l}\text { FAPESP } \\
\text { PAHO }\end{array}$ & - & - & - & - & - \\
\hline $\begin{array}{l}\text { Jair Lício } \\
\text { Ferreira Santos }\end{array}$ & USP & - & - & - & - & - & - \\
\hline $\begin{array}{l}\text { Florence Kerr- } \\
\text { Corrêa }\end{array}$ & UNESP & FAPESP & - & - & - & - & - \\
\hline $\begin{array}{l}\text { Maria Odete } \\
\text { Simão }\end{array}$ & UNESP & - & - & - & - & - & - \\
\hline $\begin{array}{l}\text { Maria Cristina } \\
\text { Pereira Lima }\end{array}$ & UNESP & - & - & - & - & - & - \\
\hline \multicolumn{8}{|c|}{$\begin{array}{l}\text { * Modest } \\
\text { ** Significant } \\
\text { *** Significant: Amounts given to the author's institution or to a colleague for research in which the author has participation, not directly to the } \\
\text { author. } \\
\text { Note: USP = Universidade de São Paulo; UNESP = Universidade Estadual Paulista; FAPESP = Fundação de Amparo à Pesquisa do Estado de } \\
\text { São Paulo. PAHO = Pan American Health Organization. } \\
\text { For more information, see Instructions for Authors. }\end{array}$} \\
\hline
\end{tabular}

References

1. Hulse GK. Alcohol, drugs, and much more in later life. Rev Bras Psiquiatr. 2002;24(1):34-41.

2. Merrick EL, Horgan CM, Hodgkin D, Garnick DW, Houghton SF, Panas L, Saitz R, Blow FC. Unhealthy drinking patterns in older adults: prevalence and associated characteristics. J Am Geriatr Soc. 2008;56(2):214-23.

3. National Institute on Alcohol Abuse and Alcoholism - NIAAA. Tenth Special Report to the U.S. Congress on Alcohol and Health: Highlights from Current Research, NIH Publication No. 00-1583, Bethesda, MD: U.S. Department of Health and Human Services; 2000.

4. Lima MCP, Simão MO, Oliveira JB, Cavariani MB, Tucci AM, Kerr-Corrêa F. Alcohol use and falls among the elderly in Metropolitan São Paulo, Brazil. Cad Saude Publica. 2009;25(12):2603-11.

5. Beullens J, Aertgeerts B. Screening for alcohol abuse and dependence in older people using DSM criteria: a review. Aging Ment Health. 2004;8(1):76-82.

6. Saunders PA, Copeland JR, Dewey ME, Davidson IA, McWilliam C, Sharma V, Sullivan C. Heavy drinking as a risk factor for depression and dementia in elderly men: findings from the Liverpool Longitudinal Community Study. Br J Psychiatry. 1991;159:213-6.

7. Mendoza-Sassi RA, Beria JU. Prevalence of alcohol use disorders and associated factors: a population-based study using AUDIT in southern Brazil. Addiction. 2003;98(6):799-804.

8. Prais HA, Loyola-Filho AI, Firmo JO, Lima-Costa MF, Uchoa E. A populationbased study on binge drinking among elderly Brazilian men: evidence from the Belo Horizonte and Bambui health surveys. Rev Bras Psiquiatr. 2008;30(2):118-23.

9. Castro-Costa E, Ferri CP, Lima-Costa MF, Zaleski M, Pinsky I, Caetano R, Laranjeira R. Alcohol consumption in late-life - the first Brazilian National Alcohol Survey (BNAS). Addict Behav. 2008;33(12):1598-601.

10. Culberson JW. Alcohol use in the elderly: beyond the CAGE. Part 2: Screening instruments and treatment strategies. Geriatrics. 2006;61(11):20-6.
11. O'Connell H, Chin AV, Hamilton F, Cunningham C, Walsh JB, Coakley D, Lawlor BA. A systematic review of the utility of self-report alcohol screening instruments in the elderly. Int $J$ Geriatr Psychiatry. 2004;19(11):1074-86

12. Buchsbaum DG, Buchanan RG, Welsh J, Centor RM, Schnoll SH. Screening for drinking disorders in the elderly using the CAGE questionnaire. $J$ Am Geriatr Soc. 1992;40(7):662-5.

13. Jones TV, Lindsey BA, Yount P, Soltys R, Farany-Enayat B. Alcoholism screening questionnaires: are they valid in elderly medical outpatients? J Gen Intern Med. 1993;8(12):674-8.

14. Joseph CL, Ganzini L, Atkinson RM. Screening for alcohol use disorders in the nursing home. J Am Geriatr Soc. 1995;43(4):368-73.

15. Morton JL, Jones TV, Manganaro MA. Performance of alcoholism screening questionnaires in elderly veterans. Am J Med. 1996;101(2):153-9.

16. Luttrell S, Watkin V, Livingston G, Walker Z, D'Ath P, Patel P, Shergill S, Dain A, Bielawska C, Katona C. Screening for alcohol misuse in older people. Int J Geriatr Psychiatry. 1997;12(12):1151-4.

17. Paz-Filho GJ, Sato LJ, Tuleski MJ, Takata SY, Ranzi CC, Saruhashi SY, Spadoni B. Use of the CAGE questionnaire for detecting alcohol use disorders in the emergency room. Rev Ass Med Brasil. 2001;47(1):65-9.

18. Taylor B, Rehm J, Aburto JT, Bejarano J, Cayetano C, Kerr-Corrêa F, Ferrand MP, Gmel G, Graham K, Greenfield TK, Laranjeira R, Lima MC, Magri R, Monteiro MG, Medina Mora MH, Munné M, Romero MP, Tucci AM, Wilsnack S. Alcohol, gender, culture and harms in the Americas: PAHO Multicentric Study final report. Washington DC: Pan American Health Organization; 2007.

19. Perfil dos idosos responsáveis pelos domicílios no Brasil 2000, 2002 [Internet]. IBGE - Instituto Brasileiro de Geografia e Estatística. [cited 2009 Dec 15]. Available from: http://www.ibge.gov.br/home/estatistica/populacao/ perfilidoso/perfidosos2000.pdf. 
20. Kerr-Corrêa F, Tucci AM, Hegedus AM, Trinca LA, de Oliveira JB, Floripes TM, Kerr LR. Drinking patterns between men and women in two distinct Brazilian communities. Rev Bras Psiquiatr. 2008;30(3):235-42.

21. Saunders JB, Aasland OG, Babor TF, de la Fuente JR, Grant M. Development of the Alcohol Use Disorders Identification Test (AUDIT): WHO Collaborative Project on Early Detection of Persons with Harmful Alcohol Consumption-II. Addiction. 1993;88(6):791-804.

22. Ewing JA. Setting alcoholism: the CAGE questionnaire. JAMA. 1984;252(14):1905-7.

23. Mayfield D, Mcleod G, Hall P. The CAGE questionnaire: validation of a new alcoholism screening instrument. Am J Psychiatry. 1974;131(10):1121-3.

24. Russell M, Bigler L. Screening for alcohol-related problems in an outpatient obstetric-gynecologic clinic. Am J Obstet Gynecol. 1979;134(1):4-12.

25. Dawe S, Mattick RP. Review of diagnostic screening instruments for alcohol and other drug use and other psychiatric disorders. Australia: National Drug Strategy. Australian Government Publishing Service; 1997.72 p.

26. Sokol RJ, Martier SS, Ager JW. The T-ACE questions: practical prenatal detection of risk-drinking. Am J Obstet Gynecol. 1989;160(4):863-71.

27. Fabri CE. Desenvolvimento e validação de instrumento para rastreamento do uso nocivo de álcool durante a gravidez (T-ACE) [tese]. Ribeirão Preto (SP): Universidade de São Paulo; 2001.

28. Kerr-Corrêa F, Tucci AM, Hegedus AM, Trinca LA, Oliveira JB, Floripes TM, Kerr LRFS. Differences in drinking patterns between men and women in Brazil. In: Obot I, Room R, editors. Alcohol, gender and drinking problems: perspectives from low and middle-income countries and drinking problems. Geneva: World Health Organization, Department of Mental Health and Substance Abuse; 2005. cap.3, p.49-68.

29. Adams WL, Barry KL, Fleming MF. Screening for problem drinking in older primary care patients. JAMA. 1996;276(24):1964-7.

30. Di Bari M, Silvestrini G, Chiarlone M, De Alfieri W, Patussi V, Pini R, Masotti G, Marchionni N. Features of excessive alcohol drinking in older adults distinctively captured by behavioral and biological screening instruments: an epidemiological study. J Clin Epidemiol. 2002;55(1):41-7.

31. Philpot M, Pearson N, Petratou V, Dayanandan R, Silverman M, Marshall J. Screening for problem drinking in older people referred to a mental health service: a comparison of CAGE and AUDIT. Aging Ment Health. 2003;7(3):171-5.

32. Bradley KA, McDonell MB, Bush K, Kivlahan DR, Diehr P, Fihn SD. The AUDIT alcohol consumption questions: reliability, validity, and responsiveness to change in older male primary care patients. Alcohol Clin Exp Res. 1998;22(8):1842-9.

33. Gómez A, Conde A, Santana JM, Jorrín A, Serrano IM, Medina R. The diagnostic usefulness of AUDIT and AUDIT-C for detecting hazardous drinkers in the elderly. Aging Ment Health. 2006;10(5):558-61.

34. Rigler SK. Alcoholism in the elderly. American Family Physician, Published by the American Academy of Family Physicians; 2000.

35. Kitchens JM. Does this patient have an alcohol problem? JAMA. 1994;272:1782-7.

36. Naik PC, Jones RG, Lilley J. How can we detect sick elderly excessive drinkers? Int J Geriatr Psychiatry. 1995;10:1063-6.

37. Mangion DM, Platt JS, Syam V. Alcohol and acute medical admission of elderly people. Age and Ageing.se 1992;21(5):362-7.

38. Moore, AA, Seeman T, Morgenstern H, Beck JC, Reuben DB. Are there differences between older persons who screen positive on the CAGE questionnaire and the Short Michigan Alcoholism Screening TestGeriatric Version? J Am Geriatr Soc. 1992;50(5):858-62.

39. Harford TC. The effects of order of questions on reported alcohol consumption. Addiction. 1994;89(4):421-4.

40. Miller WR, Crawford VL, Taylor CA. Significant others as corroborative sources for problem drinkers. Addict Behav. 1979;4(1):67-70. 